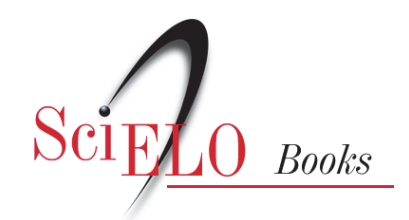

\title{
Tutoria: \\ concepções e práticas na educação a distância
}

\author{
Mayam de Andrade Bezerra
}

Ana Beatriz Gomes Carvalho

SOUSA, RP., MIOTA, FMCSC., and CARVALHO, ABG., orgs. Tecnologias digitais na educação [online]. Campina Grande: EDUEPB, 2011. 276 p. ISBN 978-85-7879-065-3. Available from SciELO Books $<$ http://books.scielo.org $>$.

\section{(1) (1)(2)}

All the contents of this work, except where otherwise noted, is licensed under a Creative Commons Attribution-Non Commercial-ShareAlike 3.0 Unported.

Todo o conteúdo deste trabalho, exceto quando houver ressalva, é publicado sob a licença Creative Commons Atribuição Uso Não Comercial - Partilha nos Mesmos Termos 3.0 Não adaptada.

Todo el contenido de esta obra, excepto donde se indique lo contrario, está bajo licencia de la licencia Creative Commons Reconocimento-NoComercial-Compartirlgual 3.0 Unported. 


\section{Tutoria: concepções e práticas na educação a distância}

\section{Mayam de Andrade Bezerra}

UEPB - Campina Grande, Paraíba mayam.uepb@yahoo.com.br

\section{Ana Beatriz Gomes Carvalho}

UEPB- Campina Grande, Paraíba anabeatrizuepb@gmail.com

\section{Introdução}

A expansão da educação a distância, na última década, e o interesse por esta forma particular de ensino e aprendizagem aumentaram de forma notável em muitos países. Especialistas de diferentes áreas começam a enxergar as possibilidades dessa modalidade de ensino. E, além disso, as universidades tradicionais começam a experimentar a educação a distância depois de ignorar por muito tempo essa modalidade educacional.

Na opinião de Peters (2003), o principal motivo para o crescente interesse na educação a distância são, obviamente, os avanços inacreditáveis na telecomunicação, juntamente com as tecnologias digitais que possibilitam vantagens logísticas e pedagógicas 
inesperadas, como por exemplo: a transmissão rápida de informações a qualquer momento e para toda parte, genuínas possibilidades para a aprendizagem autônoma, maior interatividade, mais orientação para os/as estudantes, maior individualização, melhor qualidade dos programas e maior eficácia da aprendizagem.

A EAD atualmente experimenta um crescimento e uma eficácia pedagógica sem precedentes e desponta com uma modalidade de ensino, na qual vem favorecendo a democratização do saber, oportunizando a inclusão digital e social, de alcance inimaginável.

A implementação de cursos na modalidade a distância em Universidades públicas, foi realizada a partir das orientações operacionais da Secretaria de Educação a Distância do MEC, uma vez que os cursos de graduação a distância são financiados pelo MEC na maioria das IES públicas.

Para a efetivação dessa modalidade atua uma equipe multidisciplinar que é responsável desde a produção do material até o acompanhamento dos estudantes. As categorias e funções dos profissionais desta equipe multidisciplinar apresentam traços em comum nas diferentes instituições, embora a nomenclatura possa variar ocasionalmente. Um dos profissionais que vem sendo alvo de discussões é o tutor, profissional que atua diretamente com os alunos e cuja função ainda necessita de mais clareza nas suas atribuições. Para alguns profissionais, cabe ao tutor orientar, esclarecer dúvidas e acompanhar o estudo do aluno, enquanto para outros o tutor é um professor que deve mediar todo o processo de ensino e aprendizagem. Mas qual é realmente o papel do tutor? Ele é orientador, conselheiro, motivador ou mediador?

Diante destes questionamentos, surgiu esta pesquisa cujo objetivo foi analisar as concepções e práticas da tutoria nos cursos a distância da UEPB. O presente estudo foi realizado no polo de Campina Grande-PB, que concentra seis cursos na modalidade a distância inseridos nos projetos governamentais do Pró-Licenciatura 
(Fase 1 e 2) e na UAB (Universidade Aberta do Brasil). São cursos de licenciatura em diversas áreas do conhecimento, com exceção do curso de Administração, projeto-piloto da UAB e do fórum das estatais. A amostra foi constituída por um grupo de 4 tutores/as do curso de Administração a Distância, polo Campina Grande, e 6 tutores/as dos cursos de Física, Química e Matemática da UFRN em parceria com a UEPB.

Este estudo, de natureza qualitativa, nos possibilitou compreender o fenômeno estudado em seu contexto, uma vez que o comportamento humano é significativamente influenciado pelo contexto em que está inserido. Desse modo, pudemos entender um pouco do processo no qual as pessoas constroem significados. Segundo Minayo (1999, p. 21), "a abordagem qualitativa aprofunda-se no mundo dos significados das ações e relações humanas, um lado não perceptível e não captável em equações, médias e estatísticas".

Para a obtenção dos dados, foram utilizados os seguintes instrumentos de coleta: observação livre e entrevista semi-estruturada. A observação nos conduziu a conhecer os atos, a dinâmica espontânea dos indivíduos, suas práticas e seu cotidiano, e assim possibilitou aprofundar a compreensão do fenômeno investigado. Os dados coletados na observação foram registrados em um diário etnográfico.

As entrevistas semi-estruturadas representaram o principal instrumento de coleta. Este tipo de entrevista "parte de certos questionamentos básicos, apoiados em teorias e hipóteses” (TRIVIÑOS, 1987, p. 146). Além de favorecer a espontaneidade e a liberdade de expressão, tanto do/a entrevistado/a quanto do/a entrevistador/a, enriquecendo a investigação. Os dados obtidos particularmente nas entrevistas foram analisados através da análise temática, que consiste em uma das modalidades da análise de conteúdo. 
Conforme Triviños (1987), as questões fundamentais que compõem uma entrevista semi-estruturada resultam do embasamento teórico, suposições e informações prévias sobre o fenômeno investigado, o que justifica a escolha dos informantes. Este instrumento de obtenção de dados favorece não só a descrição, mas também a explicação e a compreensão mais ampla do fenômeno estudado.

Nessa direção, elaboramos o roteiro de entrevista a ser aplicado com os sujeitos da pesquisa, de forma a assegurar que pudéssemos acrescentar perguntas de esclarecimentos, caso necessário. As entrevistas foram realizadas com 10 tutores/as, de forma individual, e gravada em áudio. Depois, foram transcritas na íntegra.

Concluída a aplicação dos instrumentos, passamos à fase de análise dos dados. Segundo Lüdke e André (1986), a análise dos dados qualitativos requer que todas as informações obtidas durante a pesquisa sejam analisadas conjuntamente. A tarefa de análise exige, num primeiro momento, que todo material coletado seja organizado em partes procurando identificar tendências e padrões relevantes, os quais serão reavaliados, buscando relações e inferências.

Os dados obtidos particularmente nas entrevistas foram analisados através da análise temática, que consiste em uma das modalidades da análise de conteúdo. Para Bardin (1977, p.105), a análise temática objetiva desvendar o que está por trás das palavras sobre as quais se debruça, e assim "descobrir os 'núcleos de sentido’ que compõem a comunicação e cuja presença ou freqüência de aparição podem significar alguma coisa para o objetivo analítico escolhido".

Ao iniciarmos a análise, optamos por identificar os/as participantes da pesquisa com a letra $\boldsymbol{T}$, acompanhado de um numeral, dessa forma, mantivemos o sigilo da sua identidade. Em seguida, separamos as entrevistas por perguntas para podermos visualizar o discurso de cada sujeito a respeito de determinado assunto. Então, 
fizemos uma "leitura flutuante", com o objetivo de conduzir a algumas questões norteadoras. Após essa leitura, verificamos alguns elementos que se repetiam e alguns divergentes. Depois dessa etapa realizamos uma leitura mais analítica, classificando algumas unidades de sentido nos discursos dos/as entrevistados/as.

\section{Educação a Distância: um novo olhar sobre a aprendizagem}

Nesta modalidade de educação, a comunicação é um elemento fundamental e ela é mediada por diversos tipos de mídias: documentos impressos, rádio, vídeo, TV, fax e o computador. Esta modalidade de educação principalmente na atualidade apóia-se fortemente na utilização das TICs e com isso amplia consideravelmente suas possibilidades. $\mathrm{O}$ avanço tecnológico permitiu que a EAD desse um salto quantitativo com relação à disponibilização de cursos em diferentes níveis de graduação, atendendo a clientelas bastante diversificadas.

A Educação a Distância apresenta uma estrutura que modifica as relações educativas decompondo em dois momentos e dois lugares, conforme ressalta Martins e Arredondo (2001) na qual o ensino passa a ser mediatizado, a aprendizagem resulta do trabalho do estudante, a reação do aluno em face do conteúdo vem indiretamente ao docente por meio da tutoria, e a interação em sala de aula é em grande parte reduzida.

Considerando que a forma de oferecer Educação a Distância não é nova, visto que essa modalidade de ensino já existe há mais de 160 anos, tendo sido iniciada pelos ingleses nas mais diferentes áreas, via correspondência postal. Além do que, no Brasil, o ensino por correspondência já completou mais de cem anos. Mas foi a partir da promulgação da Lei de Diretrizes e Bases - 9.394, de 20 de dezembro de 1996, que foi oficializada no país esta modalidade. 
Vale ressaltar que a EAD não pode ser vista como substituta da educação convencional, presencial, pois são modalidades diferentes. A Educação a Distância possui suas especificidades, se concretizando diferente da educação presencial, sobretudo no que concerne a espaciotemporalidade. De acordo com Belloni (2006), a EAD deve ser compreendida como parte de um processo de inovação educacional amplo, viabilizado pela integração das Novas Tecnologias de Informação e Comunicação aos processos educacionais.

Peters (2003) defende a idéia de que a EAD é uma modalidade de educação com objetivos, estudantes, métodos, mídias e estratégias diferentes. Ele afirma que a situação educacional, o clima de aprendizagem, os métodos de apresentação e os métodos de aquisição do conhecimento são diferentes. Para ele não há uma interação direta entre professores e estudantes, a interação é mediada por artefatos, o processo ensino-aprendizagem ocorre predominantemente, por meio do uso da linguagem escrita, ao invés da linguagem oral e tudo isso caracteriza um rompimento com a tradição acadêmica presencial.

Tentando definir a Educação a Distância, Belloni (2006) faz uma revisão de diversos autores e constata que essa definição é construída pela descrição das principais características do que seria a EaD. Ainda a esse respeito, Sarmet (2003) em sua pesquisa de mestrado faz uma análise e aponta algumas dessas características: distância entre o professor e o aluno; ruptura temporal do processo de educação; mediação por um aparato tecnológico; flexibilidade na estruturação dos conteúdos e utilização de recursos tecnológicos; ênfase na autonomia do aluno enquanto gestor do seu processo de aprendizagem; mudanças administrativas e organizacionais.

Além disso, na EAD as atividades de ensino e aprendizagem podem ocorrer em tempo síncrono e assíncrono, o que oferece ao estudante a oportunidade de desenvolver seus estudos conforme sua disponibilidade. Dessa forma, cria um espaço de ação gerenciado pelo próprio estudante, revelando outra característica desta 
modalidade de educação, que é a centralidade do estudante no processo ensino-aprendizagem. Corroborando com esta afirmativa Carvalho (2007, p. 2-3) esclarece:

[...] a flexibilidade dos horários, a não obrigatoriedade da frequência diária, a utilização do computador como ferramenta, entre outros elementos, amplia consideravelmente o leque de pessoas que podem incluir-se em um processo de formação institucional. [...] A distância física é encurtada pelas tecnologias de comunicação que conectam professores, alunos e tutores fisicamente distantes. A ampliação do tempo de estudo está diretamente relacionada com a 'quebra' da temporalidade, já que o aluno pode acessar o material em diversos momentos, inclusive de madrugada e aos domingos. As orientações e aulas estão no ar ininterruptamente e cabe ao aluno aproveitar o momento mais adequado para interagir com o material.

Vemos que o papel do professor tem sido redimensionado, em parte devido às tecnologias, mas principalmente por causa das influências do novo paradigma educacional. Nesta perspectiva, o/a professor/a deixa de ser o único detentor do conhecimento, que ora era transmitido aos estudantes e passa a mediar esse processo de aprendizagem, problematizando, instigando e intervindo para juntos construírem o conhecimento.

Na Educação a Distância, a ação educativa do professor deve estar centrada na construção de um processo educativo alicerçado na interatividade e na criatividade, na qual deverá provocar discussões, dúvidas e instigar a aprendizagem dos estudantes.

A presença de uma equipe multidisciplinar que atua de forma cooperativa para desenvolver os cursos de graduação em Instituições 
de Ensino Superior e a tutoria, objeto de nossa investigação, desempenha papel importante, sendo o elo entre os estudantes e os docentes.

Tutoria: práticas e discursos na educação a distância

Primeiramente, para entendermos como a tutoria tem sido concebida e tratada na contemporaneidade, faz-se necessário compreendermos o que dizem alguns estudiosos sobre o assunto.

Ao fazermos uma retrospectiva histórica e uma análise terminológica da palavra tutor percebemos diferentes significados que foram sendo atribuídos ao termo no decorrer da história. A palavra tutor vem do latim tutore e sua origem está relacionada à área jurídica, significando defensor, protetor, alguém que é encarregado legalmente de exercer a tutela.

No entanto, ao ser apropriada pela Educação a Distância a tutoria ganha um novo significado e passa a ser vista como um conselheiro e também um orientador de aprendizagem do aluno solitário. Mas ao analisarmos a trajetória evolutiva dos programas de EAD no Brasil desde 1967, identificamos outras concepções de tutoria que subjazem esses projetos.

Na medida em que íamos percorrendo os programas percebemos logo em 1969, no projeto da TV Educativa do Maranhão, um Tele Ensino para alunos de $5^{\mathrm{a}}$ a $8^{\mathrm{a}}$ série do ensino fundamental, na qual o papel da tutoria era de Orientador da Aprendizagem. Também identificamos no Programa da Fundação Roberto Marinho - Telecurso 2000, e no Projeto Um Salto para o Futuro que a tutoria tinha essa mesma atribuição. Já nos programas da TV Escola e no PROINFO - Programa Nacional de Informática na Educação observamos que a tutoria cabia a função de Multiplicador. Enquanto que nos programas do SENAI/SP - Serviço Nacional de Aprendizagem Industrial a tutoria era concebida como uma Monitoria. 
Também extraímos dos estudos de Peters (2003) outro modelo tutorial, que preservava em parte a essência da tutoria em sua acepção tradicional, visto que os tutores não eram docentes, mas sim conselheiros, companheiros dos estudantes, cuja função era a de assessorá-los em questões gerais, estabelecendo uma relação pessoal com eles. A tutoria era um agregado da Universidade, sendo que este não era responsável pelo ensino, era apenas um conselheiro. Desse modo a imagem da tutoria ficava atrelada a uma pessoa que dá assistência no estudo no sentido mais restrito.

Podemos perceber que existe uma diversidade terminológica e funcional em torno deste personagem. Por vezes, o termo tutoria tem sido utilizado de forma indiscriminada, causando assim uma confusão quanto ao seu papel, visto que, ora a tutoria é concebida como conselheiro/a, guia, orientador/a, multiplicador/a, instrutor/a, companheiro/a e monitor/a. É necessário uma resignificação do termo para superar a visão de tutoria como aquela que ampara, protege, guia e defende.

Estudiosos/as como Emereciano, Souza e Freitas (2001), Martins (2001), Gonzalez (2005) e Maggio (2001) defendem que o trabalho da tutoria, apesar de apresentar suas especificidades, guarda em si a essência da ação educativa desenvolvida pelo professor, é alguém essencial, que no estabelecimento de suas mediações entre o/a estudante e as informações, fornece as direções, indica caminhos, possibilita a construção do conhecimento. Esses autores optam, inclusive, por chamar o tutor de professor-tutor.

A tutoria desempenha papel fundamental na EAD, pois apenas o uso do material didático pode não garantir a aprendizagem. Desse modo, a interação com a tutoria é uma forma de se propiciar ao estudante a distância, uma relação que apenas outro sujeito, outro ser humano pode fornecer, contribuindo com sua formação, com suas experiências, com sua subjetividade. 
Nesse sentido, para compreender o significado da tutoria Souza et al. (2004, p. 5-6) esclarecem que esta pode ser entendida,

[...] como uma ação orientadora global, chave para articular a instrução e o educativo. O sistema tutorial compreende, desta forma, um conjunto de ações educativas que contribuem para desenvolver e potencializar as capacidades básicas dos/as estudantes, orientando-os a obterem crescimento intelectual e autonomia, e para ajudá-los a tomar decisões em vista de seus desempenhos e suas circunstâncias de participação como aluno. (SOUZA et al., 2004, p. 5-6)

Por isso, que a tutoria é uma peça chave na EAD, pois esta é responsável por "garantir a inter-relação personalizada e contínua dos estudantes com o sistema. Essa ação viabiliza a articulação necessária entre os elementos do processo e a consecução dos objetivos propostos", conforme ressalta Martins (2003 apud TORRES, 2007, p. 33).

Além disso, alguns estudiosos/as buscam esclarecer o papel da tutoria nos cursos de EAD. O que realmente cabe a tutoria? Mediar todo o desenvolvimento do curso, apenas orientar os estudantes em seus estudos, esclarecer dúvidas, explicar questões relativas aos conteúdos abordados e/ou avaliar o desempenho dos estudantes em todo o processo. Essas questões inquietam os/as profissionais que trabalham com EAD, visto que por mais que cada projeto de EAD tenha um modelo de tutoria, é necessário que haja elementos constitutivos que definam esse profissional.

Percorrendo parte da literatura referente a esta temática, encontramos diversos olhares sobre o ofício da tutoria. Para Gonzalez (2005, p. 12), o papel da tutoria extrapola os limites conceituais, impostos na sua nomenclatura, uma vez que, em sua função 
precípua, ele é um educador. Conforme o autor, a tutoria é "o tênue fio de ligação entre os extremos do sistema instituição-aluno. $\mathrm{O}$ contato a distância, impõe um aprimoramento e fortalecimento permanente desse elo, sem o que, perde-se o foco".

Ainda nesta perspectiva, Silveira (2005) também concebe o/a tutor/a como um educador/a, aquele profissional que faz parte da equipe multidisciplinar da $\mathrm{EAD}$, que é responsável por discutir as estratégias de aprendizagem, suscitar a criação de percursos acadêmicos, problematizar o conhecimento, estabelecendo o diálogo com o aluno e mediando o conhecimento.

Nesse sentido, podemos perceber a amplitude das atribuições da tutoria que vão além do simples acompanhamento pedagógico. A este profissional cabe criar um ambiente que possibilite a construção do conhecimento por parte dos estudantes, buscando envolvê-los ativamente no processo de aprendizagem.

Conforme o Referencial de Qualidade para a Educação Superior a Distância, documento elaborado pela Secretaria de Educação a Distância, a tutoria desempenha papel fundamental no processo educacional dos cursos superiores a distância, uma vez que as atividades desenvolvidas a distância e/ou presencialmente contribuem para o desenvolvimento dos processos de ensino e de aprendizagem, e para o acompanhamento e avaliação do projeto pedagógico. Portanto, a tutoria deve ser compreendida como um dos sujeitos que participa ativamente da prática pedagógica. (BRASIL, 2007)

Além do que foi exposto, para Blum (2004), a tutoria deveria atuar como estimulador/a, motivador/a e orientador/a do/a estudante, devendo munir-se de todos os conhecimentos para que, virtual ou presencialmente, seja o elemento que interligará os fios cognitivos, afetivos e motivacionais necessários ao rompimento das barreiras e à extrapolação dos limites que os estudantes forem encontrando no percurso. 
Observamos que nesta perspectiva a ênfase do papel da tutoria está na sua função motivadora, assim é fundamental manter o/a estudante engajado/a com o curso, evitando que os mesmos desistam. Conforme ressalta Torres (2007, p. 34):

O papel de motivador inclui a capacidade de estimular os/as estudantes em busca de respostas e de aprofundamento, de auxiliá-los nos momentos de dúvidas e dificuldades na trajetória do curso a distância, de auxiliá-los com as dificuldades acadêmicas, tecnológicas e, muitas vezes, pessoais, de ser uma presença (mesmo que virtual) capaz de romper a solidão e o isolamento experimentado pelos estudantes a distância.

Autores como Maggio (2001), Emereciano, Souza e Freitas (2001) e Martins (2001) trazem suas contribuições e defendem que a tutoria deve atuar como mediador/a do processo de ensino e aprendizagem, problematizando o conhecimento, instigando as discussões, estimulando o pensamento crítico, a capacidade de pesquisa, contribuindo para a construção da autonomia do/a estudante. Essa postura, na concepção dos/as autores, é a mais adequada, uma vez que está fundamentada numa abordagem centrada no ato de aprender.

Nesse sentido, o professor-tutor deixa de ser o ator principal e os/as estudantes, por sua vez, tornam-se mais ativos e responsáveis pela condução de sua aprendizagem. No cenário educacional que vivenciamos, esse tipo de relação é cada vez mais estimulada, uma vez que estamos imersos em um novo paradigma educacional, que exige novas formas de ensinar.

A importância e a complexidade da posição que ocupa a tutoria dentro de um sistema de EAD exige que ele possua o domínio de uma prática política educativa, formativa e mediatizada. A figura da 
tutoria deve situar-se numa posição estratégica, já que seu desempenho central é atuar como mediador entre currículo, interesses, capacidades dos estudantes.

\section{A concepção de tutoria no campo}

A análise e interpretação dos dados desta pesquisa buscam apreender a problemática com base nas reflexões e articulações com a teoria. Assim, verificar a prática pedagógica desses tutores e seus discursos a respeito da sua atuação na EAD foi fundamental para nossa análise.

As entrevistas foram realizadas seguindo um roteiro, a partir do qual extraímos as concepções dos (as) entrevistados (as) acerca de nosso objeto de estudo. Estas concepções foram categorizadas da seguinte forma:

\section{Tutor (a) Orientador (a)}

Ao serem questionados sobre qual é o papel da tutoria, os/a entrevistados/as, de um modo geral, acreditam que a principal função da tutoria é orientar os/as estudantes em suas dificuldades. E assim se expressam:

O Tutor orienta o aluno a procurar o melhor caminho pra resolver os problemas. (T2)

Tutor é um orientador que dá algumas diretrizes, não todas, mas orienta os alunos que tem dificuldade. (T3)

Essa concepção de tutoria como orientador do processo de aprendizagem dos/as estudantes é bem presente nas propostas e práticas dos cursos a distância. Pois como já ressaltamos no capítulo II, a visão tradicional de tutor é alguém que irá aconselhar, guiar e orientar para que o estudante desenvolva sua autonomia. 
No entanto, percebemos nos discursos dos/as entrevistados/ as que a ação de orientar está em seu sentido amplo. Orientar é propor caminhos, esclarecendo percursos, de forma que favoreçam ao processo de aprendizagem dos/as estudantes.

Além disso, essa ação orientadora deve possibilitar a autonomia do/a estudante, questão primordial numa educação a distância. A esse respeito Pretti (2000, p. 27) ressalta que "o tutor, respeitando a autonomia da aprendizagem de cada cursista, estará constantemente orientando, dirigindo e supervisionando o processo de ensino e aprendizagem [...]. É por intermédio dele, também que se garantirá a efetivação do curso em todos os níveis".

$\mathrm{Na}$ educação a distância a tutoria desempenha papel fundamental, visto que por meio dela que se garante a articulação de todo o sistema de ensino e aprendizagem. Logo, a ação da tutoria não deve ser vista como um mero trabalho de acompanhamento, mas também como uma orientação individualizada e cooperativa, fundamentado numa "abordagem pedagógica centrada no ato de aprender que põe à disposição do estudante adulto recursos que lhe permitem alcançar os objetivos do curso totalmente desenvolvendo a autonomia em sua caminhada de aprendizagem", conforme destaca Delise (1999 apud MARTINS; ARREDONDO, 2001, p. 172). A esse respeito, vejamos o depoimento do/a entrevistado/a:

O trabalho da tutoria é fundamental para o sucesso dessa modalidade, porque o aluno fica muito solto, a distância, e o tutor tem papel fundamental de estar articulando, motivando, apontando caminhos para aprofundar o conhecimento. (T7)

Com certeza a ação orientadora da tutoria deve ser bem planejada, para tanto é necessário traçar estratégias de orientação, levando em consideração os conhecimentos pré-existentes, interesses e objetivos dos estudantes. Além disso, a tutoria precisa ter o 
conhecimento pormenorizado do processo de aprendizagem daqueles estudantes que estão sob sua orientação. Uma vez que ele poderá planejar estratégias de encaminhamentos e esclarecimento.

Devido à redução dos contatos pessoais entre o professor e o aluno ocorrem altas taxas de abandono na EAD. Trabalhar de modo solitário predispõe o estudante a um grande desestímulo, desse modo a importância da tarefa orientadora estar apoiada em grandes princípios durante todo o processo de orientação da tutoria. Assim, Martins e Arredondo (2001, p. 192-193) ressaltam:

1. Integralidade - levar em conta as dimensões pessoais do aluno, isto é, biológica, psiquica, social e acadêmica;

2. Universalidade - dedicar-se a todos os/as estudantes sob sua tutoria, levando em conta os ritmos diversos de aprendizagem;

3. Continuidade - orientar as tarefas de modo contínuo e ao longo do processo, sem fragmentação ou interrupções;

4. Participação - manter a coordenação e a participação entre todos os professores tutores envolvidos nos diferentes cursos, para atingir os objetivos de aprendizagem com todos os/as estudantes, sem perder a identidade das diferenças individuais nos ritmos de aprendizagem.

\section{Tutor/a professor/a}

Outro aspecto apreendido nas falas dos/as entrevistados/as é a concepção de tutor como professor. Para eles a tutoria desempenha ações educativas, visto que ele é responsável pela aprendizagem dos/ as estudantes, avalia, faz a articulação entre os demais envolvidos 
no processo, entre outras atribuições. E assim comentam de forma bem enfática:

Para mim o tutor é um professor também, a gente esclarece as dúvidas, orienta e avalia. (T10)

Nós tutores somos professores que direcionamos os alunos, orientando, fazendo um elo do professor-autor e o aluno. (T1)

Segundo Gonzalez (2005) é indiscutível que a tutoria desempenha ações educativas e como tal precisa ser considerado um professor. Ainda corroborando com esta afirmativa Maggio (2001) e Emereciano, Souza e Freitas (2001) defendem que o trabalho da tutoria guarda em si a essência da ação educativa desenvolvida pelo professor, logo estes autores/as preferem denominar de professortutor.

Precisamos considerar que a prática de tutoria deve estar pautada numa perspectiva de construção do conhecimento e não embasada num modelo tradicional de ensino transmissor de conhecimento.

Para Machado e Machado (2004) é primordial se repensar nos papéis dos principais agentes envolvidos no processo de ensino e aprendizagem num curso na modalidade à distância, principalmente o papel dos professores. Precisamos ter cuidado para que não se reproduzam nos atuais ambientes de educação a distância concepções tradicionais da figura do professor, aluno e tutor.

Desse modo, o professor deve buscar fundamentar sua prática no novo paradigma, atuando como mediador da aprendizagem, abrindo canais para as intervenções, o diálogo, problematizando de fato o saber. Atuando como mediador pedagógico, o professor estará focado na aprendizagem do aluno, assumindo que ele é o centro do processo, devendo favorecer a construção individual e coletiva do saber. 
A esse respeito um/a dos/as entrevistados esclarece que o tutor é um professor, mas seu trabalho deve estar fundamentado numa nova concepção de ensino e aprendizagem e assim comenta:

O tutor é um professor, mas é um professor numa concepção mais moderna. Que na verdade hoje quando agente fala educador, educador-professor não é mais aquele que transfere conhecimento, professor é aquele que é capaz de ajudar os alunos a construir. (T7)

No entanto, alguns sujeitos desta pesquisa ressaltam com uma certa preocupação que uma das maiores dificuldades vivenciadas neste trabalho é sobre a falta de clareza nas atribuições da tutoria, por isso que ora alguns acham que o tutor é um professor, ora acreditam que não.

Em minha opinião o papel do tutor ainda está sendo reformulado, o papel, o conceito dele, pelo menos do convívio que eu tenho cada projeto o tutor tem um certo direcionamento. (T4)

Eu acho que esta questão do papel da tutoria passa pela regularização, não existe uma função definida, isso é complicado.O tutor exerce uma função tipo auxiliar de professor. Se você tiver uma função definida ai vem a questão da valorização... Ai sim vai ser reconhecido profissionalmente.(T5)

Acho tão confuso essas atribuições da tutoria. Não existe um papel definido, a gente orienta, corrige, avalia, mas não é um professor? Isso tudo é confuso e com isso não somos valorizados enquanto profissionais do Ensino Superior.(T9)

Esse assunto é um tanto polêmico sobre as reais atribuições da tutoria, é algo que precisa ser bem esclarecido. Não basta entender o 
tutor simplesmente como alguém que vai dar um suporte. É necessário definir realmente seu papel, qual é a sua função nesse processo de construção do conhecimento na modalidade a distância.

$\mathrm{Na}$ literatura sobre a EAD não existe definições claras sobre as diferenças entre os papéis do professor e do tutor. A priori, não são apresentadas as tarefas atribuídas somente a um ou outro. Para alguns autores, como Belloni (2006), a tutoria é uma das funções do professor a distância. Para Maggio (2001), no entanto, a distinção entre professor e tutor seria apenas formal. Martins e Arredondo (2001) entendem como distintos o professor autor e o professor tutor. No entanto, ambos são professores na opinião destes autores.

\section{Tutor/a motivador/a}

Em diversos momentos da entrevista percebemos que a maioria dos/as entrevistados/as se referia ao tutor como um motivador, apontando como uma das principais atribuições da tutoria é motivar os estudantes em seu processo de aprendizagem. Como podemos verificar nos depoimentos a seguir:

Temos que considerar que num curso a distância se não tivesse o tutor, a desistência seria enorme, porque é a gente que está ali, marcando com o aluno, quando ele desestimula é a gente que está ali, é esse mediador, esse estimulador... (T4)

Você precisa estar motivando, indo em busca deles, saber a situação que eles estão, as dificuldades que eles enfrentam. Se você deixar o aluno solto, ai fica complicado. (T7)

Esse pensamento da tutoria como alguém que precisa estar ali estimulando, motivando é defendido por diversos pesquisadores/ as, tais como, Emereciano, Souza e Freitas (2001), Maggio (2001) 
e Gonzalez (2005). A ação da tutoria apresenta-se como o maior meio de incentivar e manter o estudante engajado no curso, devido ao diálogo e a interação que são estabelecidos entre a tutoria e os/ as estudantes.

Além de estar sempre estimulando o estudo, o desempenho e a formação do estudante e essa interação entre tutor e estudante, que acontecem de forma individual e até coletiva, favorecem as trocas afetivas mais amplas, uma vez que o acolhimento amigável e motivador impulsiona o estudante a crescer. A esse respeito Torres (2007, p. 35) esclarece:

O papel do professor-tutor não se restringe ao auxílio para a formação acadêmica, mas se expande para a compreensão das capacidades e limitações do ser humano. Ao receber demandas de natureza afetiva, aos professores-tutores não podem simplesmente dizer aos estudantes que esta esfera não lhes compete, de alguma forma eles deverão acolher a necessidade dos estudantes, quer seja visando os aspectos econômicos e institucionais de manutenção do indivíduo no curso, quer seja visando seu papel de educador.

Então, essa relação de afetividade que deve existir entre a tutoria e os/as estudantes é algo defendido na literatura e também bastante presente nos discursos dos sujeitos desta pesquisa.

$O$ aluno se desmotiva ao longo do caminho, $e$ quem vai motivá-lo a fazer os exercícios, a procurar acessar o ambiente virtual somos nós. Tudo bem que a vontade depende dele, mas se não tiver uma pessoa que dê o suporte, se não for nós é arriscado que ele se perca no processo. (T6) 
A nossa relação é de amigo, a convivência é tão grande que a gente vai aprendendo com eles. A gente interage com eles e sente os problemas. Aprendemos reciprocamente. (T10)

Os alunos têm uma ligação grande, tudo... os problemas, as dificuldades, os avanços, tudo é com o tutor. (T1)

São pertinentes os comentários dos/as entrevistados, uma vez que, muitas vezes, os/as estudantes desistem do curso por não conseguirem ultrapassar as dificuldades do estudo autônomo. Desse modo, cabe à tutoria está constantemente motivando, sugerindo atividades que criem hábitos de estudo, incentivando a autoconfiança, independência na tomada de decisões e iniciativa para que ele possa organizar sua aprendizagem.

Além disso, para que o estudante não se sinta solitário e se engaje no curso é primordial a interação constante, através dos meios de comunicação, respeitando a individualidade dos/as estudantes, incentivando o intercâmbio entre os colegas e orientando o estudo independente do aluno. Segundo Balbé (2003), sem o freqüente contato da sala de aula presencial, os/as estudantes necessitam de algum referencial para balizar seu processo de aprendizagem, nesse caso, a tutoria representa esse referencial.

\section{Tutor/a Mediador/a}

Nos depoimentos dos sujeitos desta pesquisa, outro aspecto que nos chamou a atenção foi a visão da tutoria com um elemento que promove a articulação entre os professores das disciplinas, a instituição e o próprio estudante. Como ressaltam os/as entrevistados/as:

Para mim o papel do tutor é fazer esse elo com o professor que está a distância e o aluno, fazer essa mediação...o tutor é essa ponte. (T1) 
A gente faz esse acompanhamento de saber se $o$ aluno está realmente fazendo as atividades, quais são as dificuldades, às vezes eles têm dificuldades em determinada atividade e não sabem como chegar ao professor, a gente faz esse elo, essa ponte, a ligação entre o aluno e o professor da disciplina. (T2)

Tutor deve acompanhar, apontar caminhos, ajudar a sanar determinadas dificuldades, é ser o elo de ligação entre outros componentes. (T7)

No ensino a distância o papel da tutoria é peça chave para o desenvolvimento do processo de ensino e aprendizagem, haja vista que é através da ação da tutoria, como esclarece Martins e Arredondo (2001, p. 171) que se "garante a interrelação personalizada é contínua do aluno no sistema e se viabiliza a articulação necessária entre os elementos do processo e consecução dos objetivos propostos".

Verificamos na literatura que as funções de orientação, acompanhamento, motivação, mediação e avaliação atribuídas a tutoria se entrelaçam de forma a constituir-se um corpo de atribuições bem específicas. Assim, para diversos estudiosos como Maggio (2001), Emereciano, Souza e Freitas (2001), Martins e Arredondo (2001) e Gonzalez (2005) o papel da tutoria extrapola os limites do simples "tirador de dúvidas" ou "conselheiro", pois em sua missão precípua ele é um educador. Um educador que engajado no processo de ensino e aprendizagem vai favorecer a articulação entre estudante, instituição, especialistas, professores e tutores; possibilitar a construção individual e coletiva do conhecimento; promover a interação o diálogo, a troca de experiência; incentivar ao desenvolvimento da autonomia do/a estudante; mobilizar os/as estudantes para a busca do conhecimento de forma crítica e reflexiva; estimulando-os a participarem de atividades colaborativas e cooperativas. 
Nesta perspectiva, verificamos uma aproximação das idéias preconizadas pelos sujeitos desta pesquisa e a literatura referente ao assunto abordado. Na visão deles o/a tutor/a é:

[...] um agente que colabora com a aprendizagem do aluno, acompanhando o desenvolvimento cognitivo do mesmo, proporcionando o objetivo final de cada aprendiz que é desenvolver melhor o conteúdo apresentado. (T8)

[...] é aquele que vai participar do processo de aprendizagem do aluno, a medida que ele contribui através das orientações, intervenções, fomentando o conhecimento do aluno. (T6)

Fica evidente a complexidade do papel da tutoria, cabe a ele estabelecer uma interação constante baseada no diálogo, na qual sua atuação junto aos estudantes possibilite ser um mediador, um articulador de todo esse processo de aprendizagem. É uma figura fundamental, como ressalta Pretti (1996, p. 45).

O tutor constitui um elemento dinâmico e essencial no processo ensino-aprendizagem, oferecendo aos estudantes os suportes cognitivos, metacognitivo, motivacional, afetivo e social para que estes apresentem um desempenho satisfatório ao longo do curso. Deverá, pois, ter participação ativa em todo o processo. Por isso, é importante que se estabeleça uma vinculação dialogal e um trabalho de parceria entre o tutor, o professor/especialista e a equipe pedagógica.

Para tanto, seria ideal que a ação da tutoria estivesse pautada numa perspectiva de construção do conhecimento, tendo como foco a aprendizagem, a participação dos estudantes, a interação entre eles, a pesquisa, o debate, o diálogo; favorecendo a produção do conhecimento. 


\section{Considerações finais}

Entender um pouco das concepções de tutoria identificadas nos discursos e na prática pedagógica foi decisivo para compreendermos as concepções veiculadas pelos/as tutores/as que trabalham nestes programas. Dessa forma, ao analisarmos os relatos dos sujeitos desta pesquisa fica evidente que tutoria para eles é acima de tudo um professor que atua na EAD ativamente, e assume o papel de mediador do processo de construção do conhecimento pelo fato de intermediar as ações de ensino-aprendizagem entre o professorpesquisador, o estudante e o conteúdo curricular proposto, sendo uma ligação entre o estudante e a instituição.

Além disso, a tutoria deve atuar orientando os estudantes, de forma a favorecer a construção de sua autonomia. Percebemos que essa questão da orientação é muito forte nos discursos e prática desses sujeitos. Como também é atribuída uma grande importância ao papel de motivador que a tutoria deve desempenhar, sendo justificado pelos entrevistados em virtude das características da modalidade de ensino, para que os estudantes não se desistimulem e desistam do curso, é fundamental que a tutoria esteja sempre estimulando.

Na literatura e nos documentos oficiais da Secretaria de Educação a Distância é bem claro que a tutoria deve participar ativamente de todo o processo de ensino e aprendizagem, buscando estabelecer um vínculo de parceria e interação com os demais profissionais e estudantes; além de mediar o processo pedagógico, esclarecer dúvidas, promover espaços de construção coletiva do conhecimento, participar do processo avaliativo, orientar os estudantes em questões relacionadas ao material didático, atividades, pesquisas, entre outros.

Nesta investigação nos propusemos analisar as concepções e prática da tutoria, acredito que um primeiro passo foi dado, mas 
sentimos que este estudo é um ensaio para novas pesquisas na área, tendo em vista a importância de se discutir e explorar mais essa temática.

Por fim, esclarecemos que esta pesquisa tem a intenção de se constituir em um instrumento de reflexão. Não pretendemos ser conclusiva, ou colocar um ponto final nesta abordagem, até porque isso não seria possível, diante de tantas questões que foram surgindo durante essa caminhada. Vislumbramos, sim, novas investigações acerca dessa temática tão instigante.

\section{Referências}

BRASIL. Ministério da Educação. Referenciais de qualidade para educação superior a distância. Brasília, 2007. Disponível em: <http:// portal.mec.gov.br/seed/index.php?option=com_content\&task=view\&id= 248\&Itemid=426>. Acesso em: 20 jun. 2008.

BARDIN, L. Análise de conteúdo. Lisboa: Edições 70, 1977.

BELLONI, M. L. Educação a distância. Campinas: Autores Associados, 2006.

BLUM, E. A. A Formação de formadores na educação a distância: redescobrindo o papel do professor-tutor. 2004. 189 f. Dissertação (Mestrado em Educação) - Universidade Estadual de Ponta Grossa, Ponta Grossa, 2004.

CARVALHO, A. B. G. Os múltiplos papéis do professor em educação a distância: uma abordagem centrada na aprendizagem. In: ENCONTRO DE PESQUISA EDUCACIONAL DO NORTE E NORDESTE, 18., 2007, Maceió. Anais... Maceió: EPENN, 2007. p. 2- 12. CD-ROM.

EMERENCIANO, M. do S. J.; SOUZA, C. A. L. de; FREITAS, L. G. de. Ser Presença como Educador, Professor e Tutor. Colabora, Curitiba, v.1, 
n.1, p. 4-11, agosto de 2001. Disponível em: <http://gemini.ricesu.com. br/colabora/n1/index1.htm>. Acesso em: 20 abr. 2008.

GONZALEZ, M. Fundamentos da tutoria em educação a distância. São Paulo: Avercamp, 2005.

LUDKÉ, M.; ANDRÉ, M. E. D. A. Pesquisa em Educação: abordagens qualitativas. São Paulo: Ed. Pedagógica e Universitária, 1986.

MACHADO, L. D.; MACHADO, E. de C. O Papel da tutoria em ambientes de EAD. 2004. Disponível em: <http://www.abed.org.br/ congresso2004/ por/htm/022-TC-A2.htm>. Acesso em: 10 de jan. 2008.

MAGGIO, M. O tutor na educação a distância. In: LITWIN, E. Educação a distância: temas para o debate de uma nova agenda educativa. Porto Alegre: Artmed, 2001.p. 100-110.

MARTINS, O. B.; ARREDONDO, S. C. Teoria e prática tutorial em EAD. In: MARTINS, O. B.; POLAK, Y. N. de S. A Educação a Distância na Universidade Federal do Paraná: novos cenários e novos caminhos. Curitiba: NEAD/UFPR, 2001. p. 67-89.

MINAYO, M. C. de S. (Org.). Pesquisa Social: Teoria, método e criatividade. 11. ed. Petrópolis: Vozes, 1999.

PETERS, O. A educação a distância em transição: tendências e desafios. São Leopoldo: Unisinos, 2003.

PRETTI, O. (Org.). Educação a Distância: construindo significados. Cuiabá: NEAD/IE-UFMT; Brasília: Plano, 2000.

et al. Educação a Distância: início e indícios de um percurso. Cuiabá: NEAD/IE/UFMT, 1996.

SARMET, M. M. Análise ergonômica de tarefas cognitivas complexas mediadas por aparato tecnológico: quem é o tutor na educação a distância?. 2003. 105 f. Dissertação (Mestrado em Psicologia) 
- Universidade de Brasília, 2003. Disponível em: <http://www.unb.br/ip/ labergo/sitenovo/dissertacoes/OrientJulia/MauricioS/MauricioS.pd>. Acesso em: 20 mai. 2008.

SILVEIRA, R. L. B. L. A importância do tutor no processo de aprendizagem a distância. Revista Iberoamericana de Educación. 2005. Disponível em: <http://www.rieoei.org/deloslectores/947Barros.PDF〉. Acesso em: 20 jan. 2008.

SOUZA, C. A. et al. Tutoria na Educação a Distância. 2004. Disponível em: <http://www.abed.org.br/congresso2004/por/htm/088TC-C2.htm>. Acesso em: 10 de abr. 2008.

TORRES, C. C. A Educação a Distância e o Papel do Tutor:

Contribuição da Ergonomia. 2007. 198 f. Tese (Doutorado em Psicologia) - Universidade de Brasília, 2007. Disponível em: <http://bdtd.bce.unb. br/tedesimplificado/tde_busca/ arquivo.php?codArquivo=2319>. Acesso em: 8 mar. 2008.

TRIVIÑOS, A. N.S. Introdução à pesquisa em ciências sociais: a pesquisa qualitativa em educação. São Paulo: Atlas, 1987. 